\title{
Photosynthetic responses of 15 phytoplankton species to ammonium pulsing*
}

\author{
Joel C. Goldman and Mark R. Dennett
}

Woods Hole Oceanographic Institution, Woods Hole, Massachusetts 02543, USA

\begin{abstract}
In a series of short-term experiments on marine phytoplankton we found no evidence that transient exposure to high $\mathrm{NH}_{4}{ }^{+}$concentration led to suppression of initial photosynthesis in 13 species previously grown to steady state under $\mathrm{NH}_{4}{ }^{+}$-limitation in continuous culture. Under similar conditions we found up to $60 \%$ initial suppression of photosynthesis in the chlorophyte Nannochloris sp. and up to $32 \%$ suppression in the prasinophyte Platymonas sp. Recovery followed and was up to $90 \%$ complete by $60 \mathrm{~min}$. These results point toward rather diverse modes of coupling between transient $\mathrm{CO}_{2}$ fixation and $\mathrm{NH}_{4}{ }^{+}$uptake, but are consistent with our earlier conclusion that rapid $\mathrm{NH}_{4}{ }^{+}$uptake, but relatively undisturbed photosynthesis is the common response of marine phytoplankton exposed to ephemermal patches of $\mathrm{NH}_{4}{ }^{+}$in the pelagic environment.
\end{abstract}

\section{INTRODUCTION}

Rapid ammonium uptake by nitrogen-limited phytoplankton is a well-established phenomenon (Conway and Harrison, 1977; McCarthy and Goldman, 1979; Goldman and Glibert, 1982). It is not so clear, however, as to how photosynthesis is coupled to $\mathrm{NH}_{4}{ }^{+}$uptake under these conditions. For example, in our previous studies we preconditioned 4 marine phytoplankton species (Phaeodactylum tricornutum [TFX-1], Thalassiosira weissflogii [Actin], Chaetoceros simplex [Bbsm], Dunaliella tertiolecta [Dun]) to different degrees of $\mathrm{NH}_{4}{ }^{+}$limitation under continuous cultivation and then pulsed them with saturation levels of $\mathrm{NH}_{4}{ }^{+}$. Although $\mathrm{NH}_{4}{ }^{+}$uptake generally was significantly greater than required for balanced growth during the first minutes of incubation (Goldman and Glibert, 1982), we could find no evidence for either stimulation or suppression of photosynthesis for up to hours of incubation (Goldman et al., 1981; Goldman and Dennett, 1983). Turpin (1983), in contrast, tested $D$. tertiolecta, under conditions virtually identical to ours and found that the initial photosynthetic rate was significantly suppressed in cultures that were strongly

- Contribution No. 5695 from the Woods Hole Oceanographic Institution nitrogen-limited. Recovery was a function both of the concentration of pulsed $\mathrm{NH}_{4}{ }^{+}$and the duration of incubation.

In an attempt to resolve whether or not these grossly different results were caused by methodological or species-specific differences, we supplied Dr. Turpin with our culture of Dunaliella tertiolecta (clone Dun) which we had obtained from the culture collection of Dr. R. R. L. Guillard. Turpin's culture of D. tertiolecta, obtained from, the Northeast Pacific Culture Collection, Department of Oceanography, University of British Columbia and designated NEPCC-1, was presumed to be the Dun clone, since it originally was obtained from the WHOI culture collection (Turpin, 1983).

In addition, we expanded our studies on $\mathrm{NH}_{4}{ }^{+}$pulsing to include 11 more species (9 marine and 2 freshwater) besides the 4 marine species we tested earlier. In reviewing the literature on $\mathrm{NH}_{4}{ }^{+}$pulsing it was clear that, exclusive of our own studies, not only have a limited number of additional species been tested for their photosynthetic response to $\mathrm{NH}_{4}{ }^{+}$pulsing under conditions of nitrogen limitation, but the results have been somewhat variable (e. g. Fogg, 1956; Kanazawa et al., 1970; Lawrie et al., 1976; Thomas et al., 1976; Collos and Slawyk, 1979; Healey, 1979; Turpin, 1983). We thus suspected that the differing results among 
experimentalists might have been due as much to species-specific differences as to any other factor.

\section{MATERIALS AND METHODS}

We grew 15 phytoplankton species to steady state in $\mathrm{NH}_{4}{ }^{+}$-limited continuous cultures exactly as described before (Goldman et al., 1981; Goldman and Dennett, 1983). Thirteen species were marine, including 5 diatoms - Thalassiosira weissflogii (Actin), Phaeodactylum tricornutum (TFX-1), Chaetoceros simplex (Bbsm), Thalassiosira pseudonana (3-H), and Thalassiosira pseudonana (13-1); 3 chrysophytes - Pavlova lutheri (Mono), Isochrysis galbana (T. Iso), and Olisthodiscus luteus (Olisth); 1 cryptophyte - Chroomonas salina (3-C); 1 prasinophyte - Platymonas sp. (Platy I); and 3 chlorophytes - Dunaliella tertiolecta (Dun), Nannochloris sp. (GSB Nanno), and Chlorella capsulata (Fla E). Two species were freshwater chlorophytes Selenastrum capricomutum and Scenedesmus obliquus. All the marine species were obtained from the culture collection of R. R. L. Guillard, except $I$. galbana (T. Iso), which we obtained from S. Gallager at the Environmental Systems Laboratory at WHOI. S. capricornutum came from the US Environmental Protection Agency in Corvallis, Oregon and S. obliquus came from the laboratory of M. Gibbs at Brandeis Unversity.

We grew cultures to steady state at relatively low dilution rates $(=$ specific growth rate $\mu$ ) in either an artificial seawater (Goldman and McCarthy, 1978) or freshwater medium (Goldman and Graham, 1981) that contained $100 \mu \mathrm{g}$ atoms $\mathrm{l}^{-1}$ of $\mathrm{NH}_{4}^{+}$and $10 \mu \mathrm{g}$ atoms $\mathrm{l}^{-1}$ of $\mathrm{PO}_{4}{ }^{-3}$ to insure nitrogen limitation. Dilution rates were varied between ca 0.3 and $0.5 \mathrm{~d}^{-1}$ so that the ratio $\mu: \hat{\mu}$ (where $\hat{\mu}=$ maximum specific growth rate) always was less than 0.5 , which, according to Turpin (1983), is the relative growth rate below which suppression of photosynthesis approaches maximal levels after $\mathrm{NH}_{4}{ }^{+}$enrichment. Cultures were maintained at steady state and tested for short-term photosynthetic response in the presence of added $\mathrm{NH}_{4}{ }^{+}$at the same temperature and light intensity. Light intensities were held constant at ca $470 \mu \mathrm{E} \mathrm{m}^{-2} \mathrm{~s}^{-1}$ but several temperatures were used: $16^{\circ} \mathrm{C}$ for Dunaliella tertiolecta, Phaeodactylum tricornutum, Chaetoceros simplex, and Thalassiosira weissflogii, $25^{\circ} \mathrm{C}$ for Nannochloris sp., and $20^{\circ} \mathrm{C}$ for the remaining species. Light intensities were measured with a Biospherical Instruments QSL$1004 \pi$ sensor and quantum scalar irradiance meter.

Once steady state conditions were attained, we withdrew samples and divided them into 2 portions. The first portion was used for analyses of particulate carbon, particulate nitrogen, residual $\mathrm{NH}_{4}{ }^{+}$, and dissolved inorganic carbon (DIC). Particulate carbon and particulate nitrogen were measured with a Perkin Elmer 240 elemental analyzer on samples retained on pre-combusted glass fiber (Whatman GF/F) filters and $\mathrm{NH}_{4}{ }^{+}$was measured on the filtrate immediately after collection (McCarthy and Kamykowski, 1972). DIC was measured on refrigerated samples with a Dorhmann PR-1 carbon analyzer.

The second portion was used in a series of timecourse experiments to measure short-term $\mathrm{CO}_{2}$ fixation in the absence and presence of $\mathrm{NH}_{4}{ }^{+}$enrichment. The protocols for these experiments were identical to those used previously (Li and Goldman, 1981; Goldman et al., 1981; Goldman and Dennett, 1983). Incubation chambers were $150 \mathrm{ml}$ water-jacketed reaction vessels. Chamber contents were continuously mixed by magnetic bar stirring.

We first added $0.5 \mu \mathrm{Ci} \mu \mathrm{mol} \mathrm{DIC}-1$ of $\mathrm{H}^{14} \mathrm{CO}_{3}^{-}$and 16 $\mu \mathrm{g}$ atoms $\mathrm{I}^{-1}$ of $\mathrm{NH}_{4}{ }^{+}$to one incubation chamber and only ${ }^{14} \mathrm{C}$ to a replicate chamber. The added $\mathrm{NH}_{4}{ }^{+}$was sufficient to saturate uptake (Goldman and Glibert, 1983). The experiment was started by addition of $25 \mathrm{ml}$ of culture to each chamber. Whole culture aliquots $(1 \mathrm{ml})$ were withdrawn in approximate $10 \mathrm{~min}$ intervals over a $60 \mathrm{~min}$ incubation period for most of the experiments. Additional repeat measurements were made in a few experiments on the 4 species we tested previously (Goldman et al., 1981): 15 min single endpoint measurements on Phaeodactylum tricornutum, Chaetoceros simplex, and Thalassiosira weissflogii and both $15 \mathrm{~min}$ single end-point and $90 \mathrm{~min}$ timecourse measurements on Dunaliella tertiolecta. Samples were placed directly in glass scintillation vials containing $2 \mathrm{ml}$ methanol acidified with $5 \%$ glacial acetic acid. The vial contents were evaporated to dryness under an infrared lamp, resuspended in $1 \mathrm{ml}$ distilled water, followed by $10 \mathrm{ml}$ scintillation fluid (Scintiverse II). Radioactivity was measured directly by liquid scintillation counting on a Beckman LS-100C spectrometer.

The specific carbon rates $\mu^{\prime}(-)$ (without $\mathrm{NH}_{4}{ }^{+}$enrichment) and $\mu^{\prime}(+)$ (with $\mathrm{NH}_{4}{ }^{+}$enrichment) were determined from the relation $\underline{a} \Delta t^{-1} \ln \left[\left(\mathrm{PC}+\Delta^{14} \mathrm{C}\right) \mathrm{PC}^{-1}\right]$, where $\Delta^{14} \mathrm{C}=$ amount of labelled carbon incorporated over the period $\Delta t ; P C=$ particulate carbon concentration at the start of the incubation; $\underline{a}=$ a correction factor to account for isotopic discrimination (taken to be 1.05). Except where noted, $\mu$ ' was determined from the slope of the time-course curves.

The impact of $\mathrm{NH}_{4}{ }^{+}$enrichment on photosynthesis was calculated in 2 ways: either as a comparison of $\mu^{\prime}(+)$ with $\mu^{\prime}(-)$ or from the expression $A_{1}={ }^{14} \mathrm{C}(+)$ : ${ }^{14} \mathrm{C}(-)$ in which $\mathrm{A}_{t}$ is the accumulation factor after $t \mathrm{~min}$ incubation and ${ }^{14} \mathrm{C}(+)$ and ${ }^{14} \mathrm{C}(-)$ are, respectively, the total accumulated ${ }^{14} \mathrm{C}$ after $\mathrm{t}$ min in the presence and absence of added $\mathrm{NH}_{4}{ }^{+}$. Values of $\mathrm{A}_{t}>1$ indicate 
stimulation of ${ }^{14} \mathrm{C}$ uptake, values $<1$ indicate suppression, and values $=1$ represent no effect.

\section{RESULTS}

$\mathrm{NH}_{4}{ }^{+}$limitation was assured in virtually all experiments. Residual $\mathrm{NH}_{4}^{+}$concentrations were always undetectible $\left(<0.03 \mu \mathrm{g}\right.$ atoms $\left.\mathrm{l}^{-1}\right)$ and particulate $\mathrm{C}: \mathrm{N}$ ratios were, with one exception (Chroomonas salina), $>9$ (Table 1).

We could find no evidence for significant photosynthetic suppression in 13 of the 15 species we tested (Table 1; Fig. 1 and 2). There did appear to be some slight time-dependent increases (Fig. 1 B) or decreases in $A_{t}$ (Fig. 2 E). Although slight suppression or stimulation of photosynthesis in these studies cannot be ruled out, we suspect that such small variations are as much due to inherent limitations of the assay as they are to any real physiological effect. In none of the timecourse experiments was the initial value of $A_{t}\left(A_{10}\right)$ below 0.84 , and in fact, most values of $A_{10}$ were close to, or slightly greater than 1 (Table 1 ). Moreover, there were no substantial changes in $A_{1}$ during the course of these incubations, although in some cases where experiments were replicated the average values of $A_{t}$ varied by up to about 0.1 (Fig. $1 \mathrm{~A}$ and $1 \mathrm{E}$ ). The single end-point measurement of $\mathrm{A}_{15}$ in the diatom Thalassiosira weissflogii (Actin) was 0.81 (Table 1), but in numerous earlier studies with this species (as well as with Dunaliella tertiolecta, Phaeodactylum tricornutum, and Chaetoceros simplex) we found no evidence of even slight photosynthetic suppression after $\mathrm{NH}_{4}{ }^{+}$pulsing (see Fig. 1 and 2 in Goldman et al., 1981).

In stark contrast, we found a dramatic reduction in $\mathrm{A}_{10}$ to $<0.49$ in 4 replicate experiments with Nannochloris sp. (Table 1). This initial suppression of photosynthesis

Table 1. Steady state growth characteristics of 15 phytoplankton species precultured in $\mathrm{NH}_{4}^{+}$-limited continuous cultures and short-term photosynthetic response after enrichment with saturating $\mathrm{NH}_{4}^{+}$

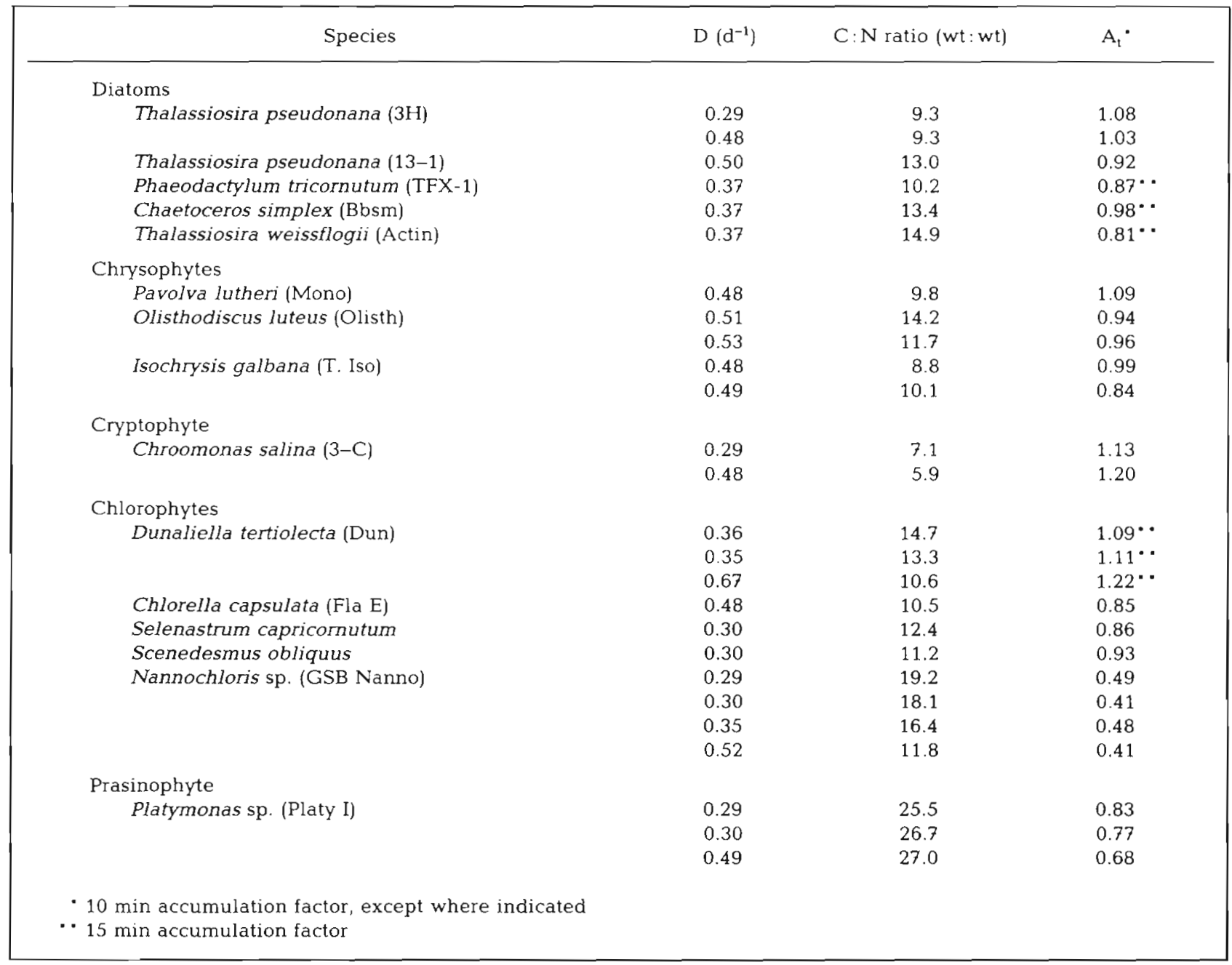



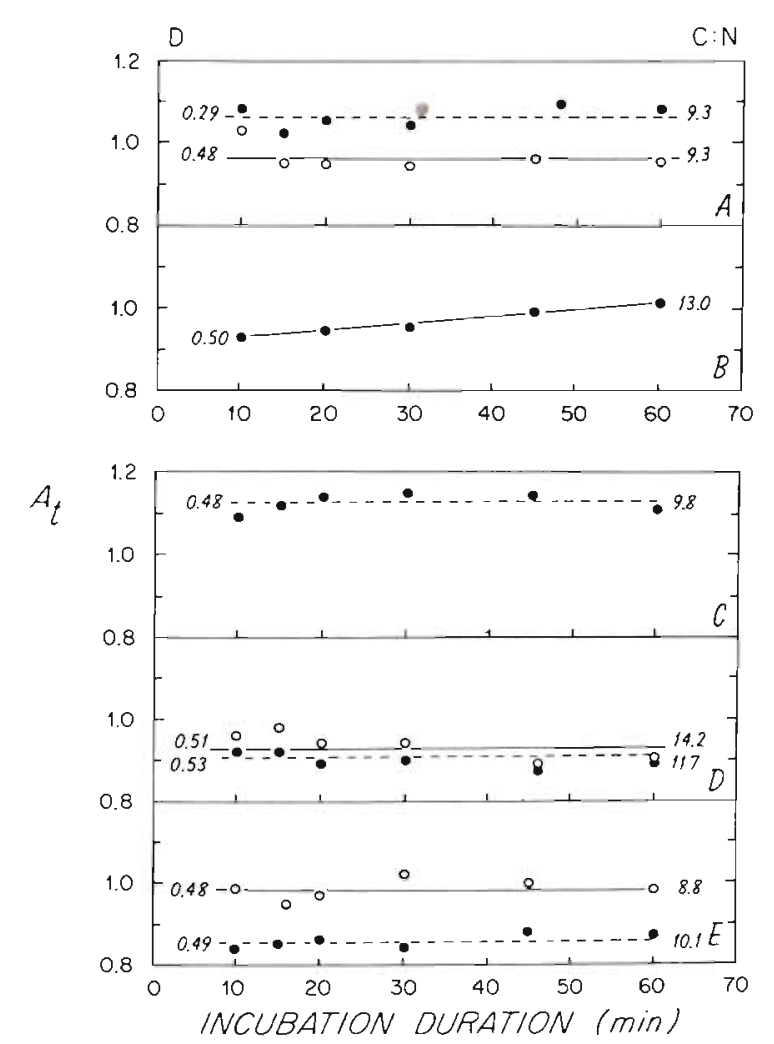

Fig. 1. Effect of $\mathrm{NH}_{4}{ }^{+}$pulsing on the accumulation factor $\mathrm{A}_{t}$ over time in phytoplankton species precultured to stated dilution rate $D$ and steady state $C: N$ ratio in continuous culture. Different symbols represent replicate experiments (A) Thalassiosira pseudonana (3H); (B) Thalassiosira pseudonana (13-1); (C) Pavlova lutheri (Mono); (D) Olisthodiscus luteus (Olisth); (E) Isochrysis galbana (T. Isol

was followed by recovery until $A_{60}$ was greater than 0.80 (Fig. 3 B). We observed a similar, but less dramatic trend in the time course data from 3 replicate studies with Platymonas sp. (Fig. $3 \mathrm{~A}$ ) - an increase from $\mathrm{A}_{10}=$ 0.68 to 0.83 to $A_{60}>0.90$. The time-dependency of recovery thus was the major criterion we used to determine whether or not there was significant initial suppression of photosynthesis.

We summarized all the data from our current and previous (Goldman et al., 1981; Goldman and Dennett, 1983) experiments in a plot of $\mu^{\prime}(+)$ versus $\mu^{\prime}(-)$ (Fig. 4). With the exception of the 2 species we identified as being sensitive to $\mathrm{NH}_{4}{ }^{+}$pulsing, all the combined data fell within or close to $\pm 10 \%$ of the line representing a non-effect, i,e. $\mu^{\prime}(+)=\mu^{\prime}(-)$.

\section{DISCUSSION}

The apparent discrepancy between our earlier results (Goldman et al., 1981) and those of Turpin (1983) seems to be resolved. Elrifi and Turpin (1985)

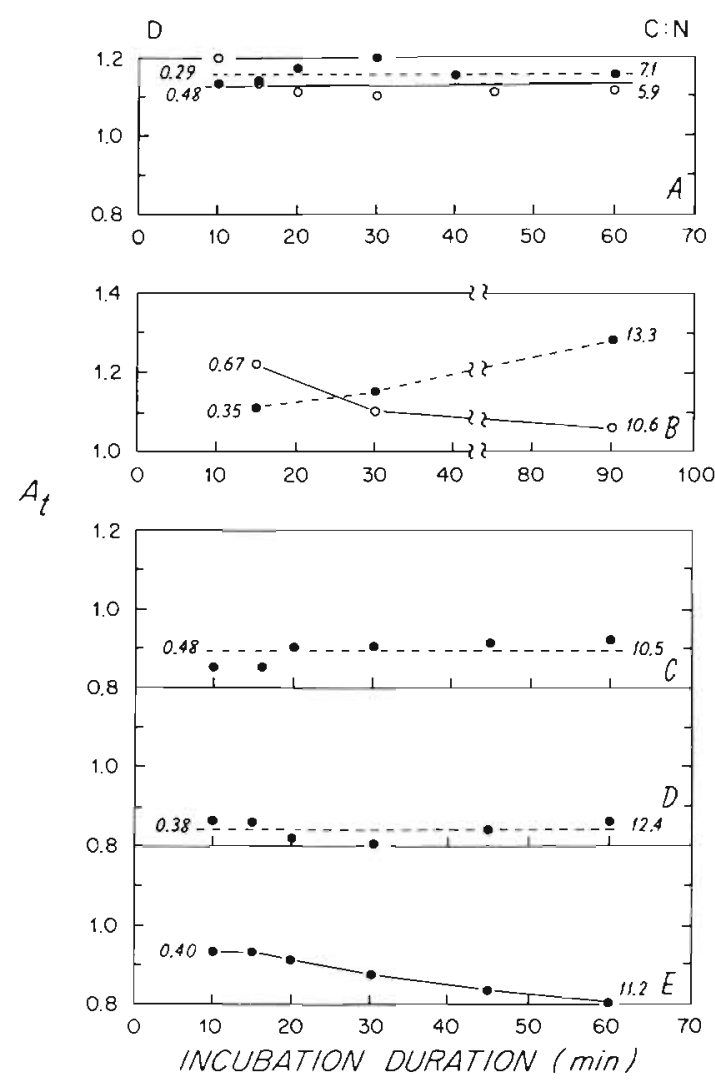

Fig. 2. Same as Fig. 1. (A) Chroomonas salina (3-C); (B) Dunaliella tertiolecta (Dun); (C) Chlorella capsulata (Fla E); (D) Selenastrum capricornutum; (E) Scenedesmus obliquus

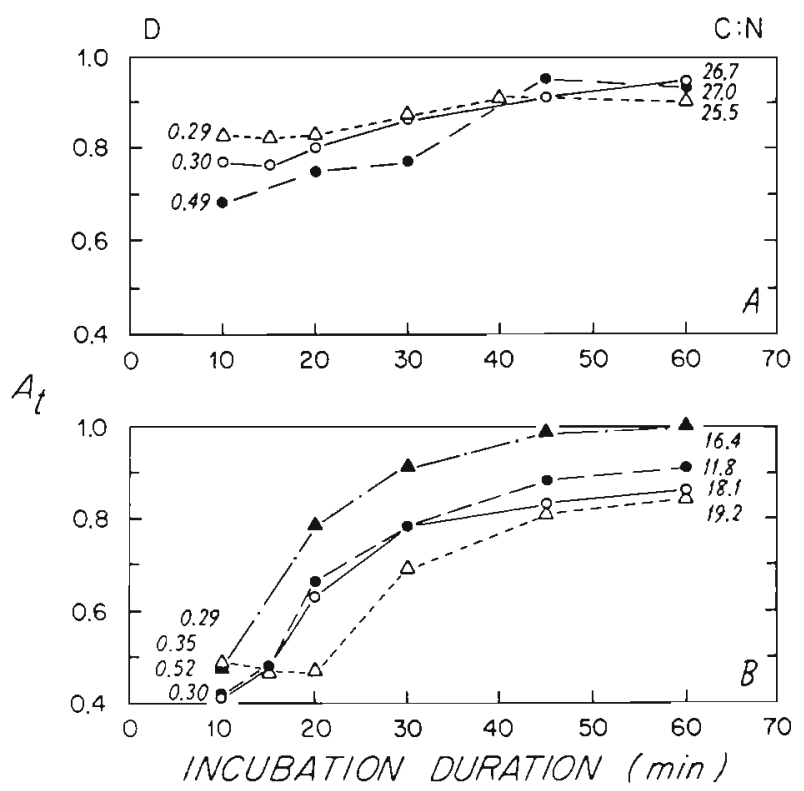

Fig. 3. Same as Fig. 1. (A) Platymonas sp. (Platy I); (B) Nannochloris sp. (GSB Nanno)

compared our clone of Dunaliella tertiolecta (Dun) with their NEPCC-1 clone under conditions identical to ours and, like us, found no evidence for $\mathrm{NH}_{4}{ }^{+}$- 


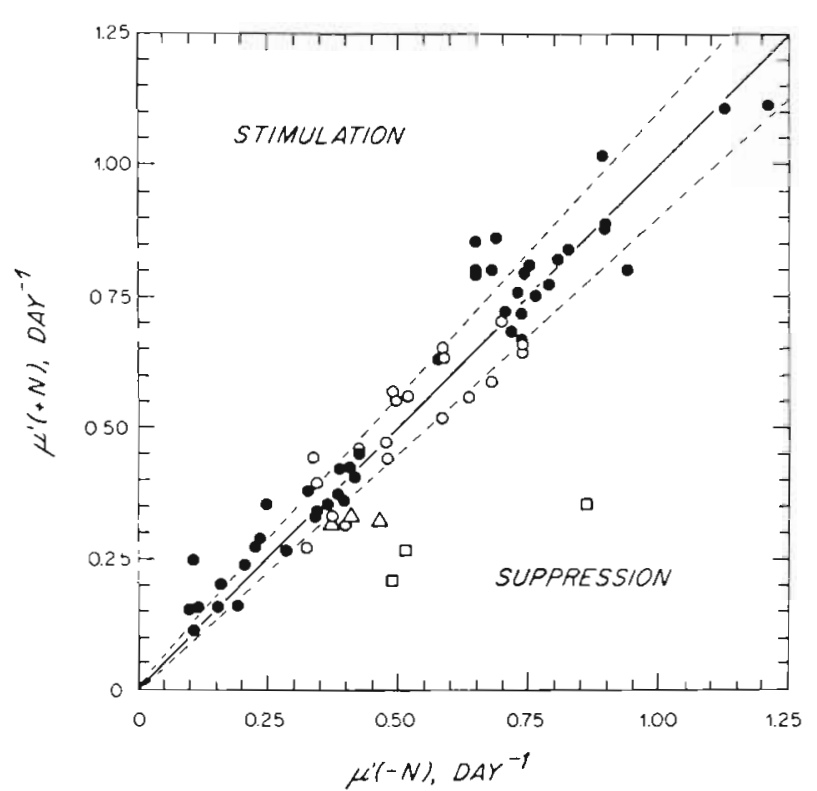

Fig. 4. Summary plot of specific carbon uptake rate $\mu^{\prime}(+)$ versus $\mu^{\prime}(-)$ for current and earlier experiments. For clarity all previous data for Dunaliella tertiolecta (Dun), Thalassiosira weissflogii (Actin), Phaeodactylum tricornutum (TFX-1), and Chaetoceros simplex (Bbsm) from Goldman et al. (1981) and Goldman and Dennett (1983) are represented by a common closed symbol $(\bullet)$. All current data are represented by open symbols: Platymonas sp. (口), Nannochloris sp. $(\Delta)$, all other data (o). Solid line represents theoretical one to one relation between $\mu^{\prime}(+)$ and $\mu^{\prime}(-)$, dashed lines represent $\pm 10 \%$ of theoretical relation

induced suppression of photosynthesis in the Dun clone; severe suppression was, however, evident once again in the NEPCC-1 clone. It seems highly likely, therefore, that the NEPCC-1 clone of $D$. tertiolecta from the Northeast Pacific Culture Collection is not the Dun clone, as previously thought (Turpin, 1983). These results, together with our current finding that photosynthesis in at least 2 marine species is inhibited for short periods by $\mathrm{NH}_{4}{ }^{+}$pulsing, point toward rather diverse modes of coupling between $\mathrm{CO}_{2}$ fixation and $\mathrm{NH}_{4}{ }^{+}$uptake in, not only different species, but clones of the same species as well.

The pattern of initial suppression we observed, followed by rapid recovery (Fig. 3) is identical to what Turpin (1983) observed in his study on the NEPCC-1 clone of Dunaliella tertiolecta and to what Healey (1979) found with the freshwater chlorophyte Scenedesmus quadricauda. Although we did not measure $\mathrm{NH}_{4}{ }^{+}$depletion over time, we suspect that the time-course of recovery of photosynthesis was correlated to some degree with the disappearance of $\mathrm{NH}_{4}{ }^{+}$ from solution, as was shown by Turpin (1983). However, in an earlier study on rapid $\mathrm{NH}_{4}{ }^{+}$uptake (Goldman and Glibert, 1982) depletion of $16 \mu \mathrm{g}$ atoms $\mathrm{l}^{-1}$ added $\mathrm{NH}_{4}{ }^{+}$by several species capable of very rapid initial $\mathrm{NH}_{4}{ }^{+}$uptake under conditions identical to those in the current study generally took far longer than 60 min. Thus the almost full recovery in photosynthesis by $60 \mathrm{~min}$ in the 2 susceptible species is not easily explained.

Healey (1979) suggested that competition for ATP and reducing electrons between $\mathrm{CO}_{2}$ and $\mathrm{NH}_{4}{ }^{+}$during the initial period of rapid $\mathrm{NH}_{4}{ }^{+}$uptake might be the cause of the initial but short-lived suppression. Turpin (1983) questioned this interpretation because, as shown by Syrett (1958) and Ohmori and Hattori (1978), recovery of initial losses of ATP during $\mathrm{NH}_{4}{ }^{+}$pulsing occurs well before depletion of added $\mathrm{NH}_{4}{ }^{+}$. Another possible explanation for this species-specific phenomenon is that cytoplasmic $\mathrm{NH}_{3}$ can be very toxic and, unless assimilated and metabolized very rapidly, could lead to initial inhibition of photosynthesis (Bassham, pers. comm.). $\mathrm{NH}_{4}{ }^{+}$concentrations per cell volume are known to reach molar concentrations (Wheeler, 1983) and most likely are even higher in individual cellular compartments. Thus even though cytoplasmic pH may be no higher than external pH (ca 8). sufficient cytoplasmic $\mathrm{NH}_{3}$ could be produced to cause significant reductions in photosynthesis. Species-specific differences in the rates and mechanisms by which $\mathrm{NH}_{4}{ }^{+}$is transported across the cell membrane, stored within the cytoplasm (or vacuoles), and finally assimilated into amino acids may thus be important factors governing how $\mathrm{CO}_{2}$ fixation is coupled to rapid removal of exogenous $\mathrm{NH}_{4}{ }^{+}$.

In trying to gauge the ecological significance of this form of transient behavior in phytoplankton it is extremely important to distinguish between $\mathrm{NH}_{4}{ }^{+}$and $\mathrm{NO}_{3}{ }^{-}$as substrates that might compete with $\mathrm{CO}_{2}$ for available energy in the light. Most likely, $\mathrm{NO}_{3}{ }^{-}$addition has a profoundly different effect on the photosynthetic apparatus than does $\mathrm{NH}_{4}{ }^{+}$enrichment, particularly since it is well-established that competition between $\mathrm{NO}_{3}{ }^{-}$and $\mathrm{CO}_{2}$ for reducing electrons occurs when cells are suddenly exposed to high $\mathrm{NO}_{3}^{-}$levels (Syrett, 1981) and that $\mathrm{NO}_{3}{ }^{-}$uptake and assimilation require substantially more energy than needed for equivalent $\mathrm{NH}_{4}{ }^{+}$processes. Certainly, the evidence for $\mathrm{NO}_{3}{ }^{-}$suppression of photosynthesis among a diverse group of phytoplankton species is compelling (Thomas et al., 1976; Collos and Slawyk, 1979; Terry, 1982; Hipkin et al., 1983; Elrifi and Turpin, 1985), although exceptions have been noted, e.g. the freshwater chlorophyte Ankistrdesmus braunii (Elrifi and Turpin, 1985) and the marine diatom Chaetoceros simplex (Goldman and Dennett, 1983).

Our interest has been focused primarily on the ways in which transient $\mathrm{NH}_{4}{ }^{+}$uptake affects photosynthesis since recycled $\mathrm{NH}_{4}{ }^{+}$is the major nitrogen source found in pelagic surface waters. Thus, there is no 
disagreement that $\mathrm{NH}_{4}{ }^{+}$-induced suppression of shortterm photosynthesis has been found in several phytoplankton species - interestingly, all chlorophytes or related species (Thomas et al., 1976; Healey, 1979; Turpin, 1983; Elrifi and Turpin, 1985). Our own evidence that only 1 chlorophyte, Nannochloris sp., and a closely related prasinophyte, Platymonas sp., out of a diverse group of 15 phytoplankton species we examined, were sensitive to $\mathrm{NH}_{4}{ }^{+}$pulsing, however, leads us to reconfirm our earlier conclusion (Goldman et al., 1981) that rapid $\mathrm{NH}_{4}{ }^{+}$uptake, but relatively undisturbed $\mathrm{CO}_{2}$ fixation, is the common response of marine phytoplankton exposed to ephemeral patches of $\mathrm{NH}_{4}{ }^{+}$in the pelagic environment.

Acknowledgement. This study was supported by Grants No. OCE82-2576 and OCE83-8578 from the National Science Foundation.

\section{LITERATURE CITED}

Collos, Y, Slawyk, G. (1979). ${ }^{13} \mathrm{C}$ and ${ }^{15} \mathrm{~N}$ uptake by marine phytoplankton. I. Influences of nitrogen source and concentration in laboratory cultures od diatoms. J. Phycol. 15: $186-190$

Conway, H. L., Harrison, P. J. (1977). Marine diatoms grown in chemostats under silicon or ammonium limitation. 4. Transient response of Chaetoceros debilis, Skeletonema costatum, and Thalassiosira gravida to a single addition of the limiting nutrient. Mar. Biol. 43: 33-43

Elrifi, I. R., Turpin, D. H. (1985). Transient photosynthetic responses to nitrogen addition in nitrogen limited microalgae. Mar. Ecol. Prog. Ser. 20: 253-258

Fogg, G. E. (1956). Photosynthesis and formation of fats in a diatom. Ann. Bot. 20: 265-285

Goldman, J. C., Dennett, M. R. (1983). Effect of nitrogen source on short-term light and dark $\mathrm{CO}_{2}$ uptake by a marine diatom. Mar. Biol. 76: 7-15

Goldman, J. C., Glibert, P. M. (1982). Comparative rapid ammonium uptake by four species of marine phytoplankton. Limnol. Oceanogr 27: 814-827

Goldman, J. C., Glibert, P. M. (1983). Kinetics of inorganic nitrogen uptake by phytoplankton. In: Carpenter, E. J., Capone, D. G. (ed.) Nitrogen in the marine environment. Academic Press, New York, p. 233-274

Goldman, J. C., Graham, S. J. (1981). Inorganic carbon limitation and chemical composition of two freshwater green microalgae. Appl. environ. Microbiol. 41: 60-70
Goldman, J. C., McCarthy, J. J. (1978). Steady state growth and ammonium uptake of a fast-growing marine diatom. Limnol. Oceanogr. 23: 695-703

Goldman, J. C., Dennett, M. R., Riley, C. B. (1981). Marine phytoplankton photosynthesis and transient ammonium availability. Mar. Biol. Lett. 2: 323-331

Healey, F. P. (1979). Short-term responses of nutrient-deficient algae to nutrient addition. J. Phycol. 15: 289--299

Hipkin, C. R., Thomas, R. J., Syrett, P. J. (1983). Effects of nitrogen deficiency on nitrate reductase, nitrate assimilation and photosynthesis in unicellular marine algae. Mar. Biol. 77: 101-105

Kanazawa, T., Kanazawa, K., Kirk, M. R., Bassham, J. A (1970). Difference in nitrate reduction in light and dark stages of synchronously grown Chlorella pyrenoidosa and resultant metabolic changes. Pl. Cell Physiol., Tokyo 11: $445-452$

Lawrie, A. C., Codd, G. A., Stewart, W. D. P. (1976). The incorporation of nitrogen into products of recent photosynthesis in Anabaena cylindrica Lemm. Arch. Mikrobiol. 107: $15-24$

Li, W. K. W., Goldman, J. C. (1981). Problems in estimating growth rates of marine phytoplankton from short-term ${ }^{14} \mathrm{C}$ assays. Microbiol. Ecol. 7: 113-121

McCarthy, J. J., Goldman, J. C. (1979). Nitrogenous nutrition of marine phytoplankton in nutrient-depleted waters. Science, N. Y. 23: 670-672

McCarthy, J. J., Kamykowski, D. (1972). Urea and other nitrogenous nutrients in La Jolla Bay during February, March, and April, 1970. Fish. Bull. U. S. 70: 1261-1274

Ohmori, M., Hattori, A. (1978). Transient changes in ATP pool of Anabaena cylindrica associated with ammonium assimilation. Arch. Mikrobiol. 117: 17-20

Syrett, P. R. (1958). Respiration rate and internal adenosine triphosphate concentrations in Chlorella. Arch. Biochem. Biophys. 75: 117-124

Syrett, P. R. (1981). Nitrogen metabolism of microalgae. In: Platt, T (ed.) Physiological bases of phytoplankton ecology. Can. Bull. Fish. Aquat. Sci. 210: 182-210

Terry, K. L. (1982). Nitrate uptake and assimilation in Thalassiosira weissflogii and Phaeodactylum tricornutum: interactions with photosynthesis and with the uptake of other ions. Mar. Biol. 69: 21-30

Thomas, R. J., Hipkin, C. R., Syrett, P. J. (1976). The interaction of nitrogen assimilation with photosynthesis in nitrogen-deficient cells of Chlorella. Planta (Berl.) 133: 9 -13

Turpin, D. H. (1983). Ammonium induced photosynthesis in nitrogen limited Dunaliella tertiolecta (Chlorophyta). J. Phycol. 19: 70-76

Wheeler, P. A. (1983). Phytoplankton nitrogen metabolism. In: Carpenter, E. J., Capone, D. C. (ed.) Nitrogen in the marine environment. Academic Press, New York, p. 309-346 